\title{
AVALIAÇÃO QUANTITATIVA DO POTENCIAL DE REÚSO NO ESTADO DE MINAS GERAIS
}

\author{
QUANTITATIVE ASSESSMENT OF THE REUSE POTENTIAL IN THE STATE OF MINAS \\ GERAIS
}

Marília Carvalho de Meloab, Marcelo da Fonseca ${ }^{a}$, Lilia Aparecida Castroa,

Renata Batista Ribeiroab, Fabrício Lisboa Vieira Machadoa

aSecretaria de Estado de Meio Ambiente e Desenvolvimento Sustentável (IGAM / MG), ' Universidade Vale do Rio Verde,

prof.marilia.melo@unincor.edu.br,.marcelo.fonseca@meioambiente.mg.gov.br, lilia.castro@meioambiente.mg.gov.br, renata.ribeiro@meioambiente.mg.gov.br, fabricio.machado@meioambiente.mg.gov.br

Submissão: 03 de março de 2021 Aceitação: 1 de julho de 2021

\section{Resumo}

Um dos principais desafios para a gestão das águas na atualidade diz respeito à relação inversa entre o aumento da demanda e a redução da disponibilidade do recurso. Nesse sentido, deverão ser adotadas medidas, por parte do poder público, capazes de enfrentar os desafios existentes e fomentar a busca por fontes alternativas de água. Com base nisso, o presente artigo tem como objetivo discutir o potencial de reúso de água a partir de efluente tratado, em Minas Gerais, para atendimento às demandas, com foco na quantidade disponível e necessária. Para tanto, o artigo percorreu três etapas, em que foram avaliadas a disponibilidade de efluente para reúso em cenários atual e futuro, a demanda total por água nas bacias hidrográficas do estado e a razão entre a disponibilidade de efluente de esgoto doméstico para reúso e a demanda existente regionalmente. Em todas as etapas, analisaram-se dados quantitativos de instituições reguladoras, representados por mapas de síntese dos cenários. Os resultados revelaram que Minas Gerais trata somente $43,7 \%$ do total de esgoto gerado, cujos maiores indicadores estiveram concentrados nas bacias dos rios das Velhas (SF5), Paraopeba (SF3) e Araguari (PN1), regiões mais populosas do estado. Das bacias citadas, apenas Velhas e Araguari possuem capacidade de tratar acima de $50 \%$ do esgoto gerado, o que explicita a dificuldade de atender as metas de universalização do tratamento. Do ponto de vista da demanda pelo uso da água, as bacias da região central do estado se destacaram pelos montantes captados para abastecimento público, enquanto as bacias do Triângulo Mineiro e Noroeste se destacaram os usos agropecuários, com até $96 \%$ do total captado. Isso revela importante polo regional para incentivo ao reúso de água, tendo em vista as exigências dos padrões de qualidade e o potencial do volume de esgoto tratado para atender até $54 \%$ dos usos agrícolas.

Palavras-Chave: Reúso; Efluentes Domésticos; UASB; Demanda hídrica.

\section{Abstract}

One of the main challenges for water management today is associated with the relationship between increased demand and reduced availability of the resource, as highlighted by authors and regulatory institutions. In this sense, measures should be taken by the public authorities capable of facing the existing challenges and promoting the search for alternative sources of water. Based on this, this article aims to discuss the potential for reusing water in Minas Gerais to meet demands, focusing on the relationship between available and necessary quantity. To this end, the article went through three stages, in which the availability of effluent for reuse in current and future scenarios was evaluated, the total demand for water in the state's hydrographic basins and the ratio between the availability of domestic sewage effluent for reuse and the existing demand regionally. In all stages, quantitative data from regulatory institutions were evaluated, represented by synthesis maps of the scenarios. The results revealed that Minas Gerais treats only $43.7 \%$ of the total sewage generated, whose main indicators were concentrated in the basins of the 
rivers Velhas (SF5), Paraopeba (SF3) and Araguari (PN2), the most populous regions of the state. Of the basins mentioned, only Velhas and Araguari have the capacity to treat over $50 \%$ of the sewage generated, which explains the difficulty of meeting the goals of universal treatment. From the point of view of the demand for water use, the basins in the central region of the state stood out for the amounts raised for public supply, while in the basins of the Triângulo Mineiro and the Northwest the agricultural uses stood out, with up to $96 \%$ of the total captured. This reveals an important regional pole to encourage the reuse of water, in view of the requirements of quality standards and the potential of the volume of treated sewage to meet up to $54 \%$ of agricultural uses.

Keywords: Reuse; Domestic Effluents; UASB; Water demand.

\section{INTRODUÇÃO}

A relação entre oferta e demanda de água é um dos principais desafios da humanidade, considerando a quantidade disponível no mundo e a tendência de aumento de uso para as diversas finalidades (ALKAISI et al., 2017). Segundo o relatório mundial das Nações Unidades sobre o desenvolvimento dos recursos hídricos 2019, estima-se que a demanda global de água continuará aumentando até 2050, o que representa um acréscimo de 20 a $30 \%$ do nível atual (UN WORLD WATER, 2016; KONCAGÜL et al., 2019).

No Brasil, o cenário se assemelha. Apesar de possuir de $12 \%$ a $16 \%$ da reserva de água mundial, sua disponibilidade não é distribuída de forma uniforme em seu território. De $260 \mathrm{mil} \mathrm{m}^{3} / \mathrm{s}$ de água, aproximadamente, que correm pelo território brasileiro, $80 \%$ estão na região amazônica, onde existe a menor parcela da população e menor demanda de uso de água (ANA, 2017; ANA, 2019a).

As regiões brasileiras apresentam contextos climáticos e socioambientais bastantes diversos em relação aos recursos hídricos. Algumas regiões convivem historicamente com as secas, como o semiárido brasileiro; outras possuem demanda que ultrapassa a capacidade dos sistemas hídricos, o que tornam ainda mais incertas as análises de tendência de impacto no ciclo hidrológico decorrente da mudança do clima em escalas geográficas específicas (PEREIRA et al., 2020). De acordo com a ANA (2018), dos 5.570 municípios brasileiros, $51 \%$ já decretaram "Situação de Emergência" ou "Estado de Calamidade Pública", devido à seca ou estiagem, pelo menos uma vez entre 2003 e 2015; sendo que $48 \%$ dos municípios decretaram emergência ou calamidade pública devido a cheias pelo menos uma vez, entre 2003 e 2017 (ANA, 2018).

Quanto ao uso de água no Brasil, o Atlas Irrigação, publicado pela Agência Nacional de Águas e Saneamento Básico (ANA), aponta que a agricultura irrigada é o setor mais consumidor de água no Brasil e no Mundo, respondendo por aproximadamente $50 \%$ do uso de água bruta proveniente de mananciais superficiais e subterrâneos, com projeção de aumento de até $76 \%$ e potencial de expansão estimado em 4,2 Mha, até 2030 (ANA, 2021a).

Em Minas Gerais, apurou-se que, no período de 1999 a 2008, foram emitidas 4.212 portarias de outorgas e, de 2009 a 2018, 16.924 portarias (IGAM, 2020). Dentre os usos regularizados, pode-se observar a seguinte divisão entre as finalidades antrópicas: 15\% para abastecimento público, $9 \%$ para consumo industrial, $72 \%$ para agropecuária (irrigação, dessedentação de animais, aquicultura), $1 \%$ outros usos e $3 \%$ não houve informação.

Ainda segundo dados do Igam, até o ano de 2019, houve a declaração oficial de 67 áreas de conflito, no estado de Minas Gerais, com maior concentração nas regiões do triângulo mineiro e noroeste, 0 que demanda ainda mais aprimoramento na gestão dos recursos hídricos, em razão do comprometimento da vazão outorgada que a declaração de área de conflito acarreta (IGAM, 2019; FONSECA et al., 2020).

Com esse contexto, é importante que sejam adotadas medidas capazes de enfrentar os desafios existentes quanto à diminuição da oferta de água, equidade em sua distribuição e consumo consciente. Gerir um recurso tão vital em um estado com múltiplas realidades ambientais é um grande desafio para o poder público e para a sociedade, que devem se articular em busca de soluções multifacetadas e em diferentes níveis de complexidade (IGAM, 
2018), passando, necessariamente, pela busca por fontes alternativas de água (MELO et al., 2020).

É nesse cenário que a utilização de fontes alternativas se configura como um instrumento de segurança hídrica para ampliação da oferta de água, dentre as quais podemos citar o reúso (PINTO et al., 2014; ANGELAKIS et al., 2018).

O reúso de água pode ser definido como o aproveitamento de águas residuárias previamente utilizadas, uma ou mais vezes, em alguma atividade humana - para suprir a necessidade de outros usos. Essa alternativa pode ser direta ou indireta, bem como decorrer de ações planejadas ou não (MOURA et al., 2020).

A água proveniente do reúso pode ser potencialmente utilizada para usos agrícolas e irrigação paisagística, reutilização industrial, recarga, combate a incêndios, limpeza de ruas, bem como para usos recreativos e ecológicos (HELMECKE et al., 2020).

De acordo com Pereira et al. (2020), o reúso de água já vem sendo utilizado em vários lugares do mundo, em especial, em Israel, na Califórnia, na Jordânia e na Arábia Saudita. Em Israel e na Jordânia, mais de $75 \%$ da vazão de efluente sanitário é reutilizada para irrigação; na Califórnia, o reúso chega a representar $10 \%$ da vazão de retirada; e na Arábia Saudita $30 \%$ do efluente sanitário municipal é reutilizado, sendo que em todos esses lugares existem planos e metas audaciosas de ampliação da prática do reúso para 2030.

Projetos inovadores de reúso de água em todo o mundo têm mostrado que tecnologias podem ser implementadas visando ao tratamento de águas residuais para quase qualquer qualidade necessária, incluindo usos altamente sensíveis, como a água potável e usos industriais, como visto pelos autores anteriormente citados.

No Brasil, de um modo geral, a falta de legislação específica e a ausência de orientações técnicas para a implantação dos sistemas adequados têm restringido a aplicação ampla da água de reúso. Além disso, em algumas regiões, a água de reúso tem sido utilizada para fins agrícolas de maneira informal e não planejada, sem garantir a segurança ambiental e de saúde pública (MOURA et al., 2020). Apesar disso, em razão da importância do tema, o Brasil vem adotando medidas para regulamentar e fomentar a prática do reúso no país.

Em 28 de novembro de 2005, o Conselho
Nacional de Recursos Hídricos (CNRH) publicou a Resolução nํ5ㄴ 54 que estabeleceu modalidades, diretrizes e critérios gerais para a prática de reúso direto não potável de água (BRASIL, 2005). Em 16 de novembro de 2010, o CNRH editou a Resolução no 121 para estabelecer diretrizes e critérios para a prática de reúso direto não potável de água somente na modalidade agrícola e florestal, condicionando que o reúso deverá observar critérios e procedimentos estabelecidos pelo órgão ou entidade competente e que não pode causar danos ao meio ambiente e à saúde pública (BRASIL, 2010). Contudo, as normas citadas apenas estabelecem diretrizes gerais, que por si só não possibilitam a implementação do reúso, por não estabelecerem métricas relacionadas aos padrões dos efluentes a serem utilizados em função do uso a ser destinado, dificultando a disseminação da prática no país (SANTOS et al., 2020).

Mais recentemente, a Lei no 14.026 de 15 de julho de 2020 (BRASIL, 2020), que atualiza o marco legal do saneamento básico, destacou o reúso de água como tema de regulamentação, por meio de normas de referência pela ANA. Pode-se entender a função de fomento ao reúso do novo marco do saneamento também na perspectiva de que a universalização propiciará um aumento de disponibilidade de efluentes de estações de tratamento de esgoto para ampliação do reúso.

Do ponto de vista da produção, segundo Silva Jr. et al. (2019), das 1.287 estações de tratamento de esgotos existentes na região Sudeste brasileira, somente quinze apresentam projetos institucionalizados de reúso e apenas nove $(0,7 \%)$ disponibilizam dados quantitativos a respeito da produção, o que demonstra ser grande o potencial de avanço e consolidação da prática no país.

No âmbito do estado de Minas Gerais, no dia 18 de junho de 2020, foi aprovada a Deliberação Normativa $n^{\circ} 65$ do Conselho Estadual de Recursos Hídricos de Minas Gerais (CERH-MG), que regulamenta o reúso direto de água não potável proveniente de Estações de Tratamento de Esgotos (ETEs) de sistemas públicos e privados e dá outras providências (MINAS GERAIS, 2020). Por meio da publicação da referida norma, os efluentes sanitários tratados passaram a poder ser utilizados em: i) atividades agrossilvipastoris; ii) usos urbanos, como na lavagem de praças, ruas e estacionamentos, 
veículos e uso predial comercial ou industrial (restrito a descargas sanitárias); iii) usos urbanos limitados, como lavagem de veículos especiais, controle de poeira, combate a incêndio, desobstrução de galerias de água pluvial e rede de esgoto; iv) usos para fins ambientais, como em projetos de recuperação florística ou de áreas degradadas, em áreas cujo acesso seja controlado; e v) usos industriais, como em operações e processos industriais, na construção civil, na mineração, entre outros.

A regulamentação da prática da fertirrigação no estado possibilita atender tanto a demanda hídrica, como as demandas nutricionais de plantio, possibilitando a substituição de fertilizantes minerais, sem o comprometimento do solo e das águas subterrâneas (SANTOS et al., 2020; SMOL et al., 2020), ampliando a disponibilidade hídrica, além propiciar a redução do lançamento de esgotos nos recursos hídricos receptores.

A prática do reúso possui, também, outros benefícios, tais como: i) evitar a descarga de esgotos em corpos de água; ii) preservar recursos subterrâneos, principalmente em áreas onde a utilização excessiva de aquíferos provoca intrusão de cunha salina ou subsidência de terrenos; iii) permitir a conservação do solo, através da acumulação de "humus" e aumentar a resistência à erosão; iv) contribuir, principalmente em países em desenvolvimento, para o aumento da produção de alimentos, elevando, assim, os níveis de saúde, qualidade de vida e condições sociais de populações associadas aos esquemas de reúso (VOULVOULIS, 2018; HESPANHOL, 2008).

O aumento da prática do reúso, além de ser um instrumento de segurança hídrica, propicia a obtenção de vantagens econômicas ao setor de saneamento e agricultura e possibilita melhorias ambientais e das condições de saúde. É necessário, portanto, que barreiras institucionais, sociais e econômicas sejam vencidas, de forma a possibilitar a implementação sustentável e disseminada da política de reúso de água baseada na economia circular (SGROI et al., 2018).

O presente artigo tem o objetivo de discutir o potencial de reúso no estado de Minas Gerais, para atendimento das demandas regionais de uso da água, em uma perspectiva de quantidade disponível e quantidade necessária.

\section{METODOLOGIA}

A fim de avaliar o potencial de reúso de água no estado de Minas Gerais e estabelecer uma discussão entre oferta e demanda pelo uso da água, em termos quantitativos, foram estabelecidas três etapas metodológicas.

A primeira etapa identificou a disponibilidade de efluente para o reúso em um cenário atual e futuro. Na segunda, avaliou-se a demanda total por água nas bacias hidrográficas do estado, assim como se qualificou a demanda por finalidade de uso. Por fim, na terceira etapa, realizou-se uma avaliação entre a disponibilidade de efluente de esgoto doméstico tratado para reúso e a demanda existente regionalmente.

A partir da avaliação da disponibilidade quantitativa de efluentes para o reúso, foi realizada uma discussão conceitual se os requisitos de qualidade dos efluentes de estações de tratamento de esgoto operadas atualmente poderiam atender aos requisitos de qualidade para os usos múltiplos, conforme estabelecido pelos padrões normativos.

A delimitação espacial para análise estabelecida foi as Unidades de Planejamento e Gestão de Recursos Hídricos (UPGRH), conforme Deliberação Normativa (DN) do Conselho Estadual de Recursos Hídricos (CERH) n006/2002 (MINAS GERAIS, 2002).

Para subsidiar a avaliação dos cenários de reúso da água em Minas Gerais, foram elaborados mapas temáticos analíticos e de síntese, contendo a distribuição e a quantificação das condições de geração e tratamento de esgoto nas UPGRHs. Os mapas foram produzidos a partir da junção espacial (join) da camada de informação geográfica das UPGRHs, com informações tabulares advindas de fontes como o Sistema Nacional de Informações sobre Saneamento (SNIS) e o Instituto Mineiro de Gestão das Águas (IGAM). Todas as operações foram realizadas no Sistema de Informação Geográfica de código-aberto QGIS, versão 3.16 Hannover. Demais convenções cartográficas foram extraídas da Infraestrutura de Dados Espaciais do Sistema Estadual de Meio Ambiente e Recursos Hídricos de Minas Gerais - IDESisema.

\section{1 - Avalição da disponibilidade de efluentes para reúso}


Realizou-se uma avaliação do potencial de reúso de água desenvolvida em dois cenários. 0 primeiro cenário considerou o esgoto coletado, e, para essa estimativa, foram utilizados dados do Atlas Esgotos (ANA, 2017). O segundo cenário considerou o esgoto gerado no estado, mesmo que não tratado. Esse cenário tem o objetivo de estimar um potencial futuro de oferta de reúso de água, tendo em conta as metas de universalização do tratamento de esgoto $(90 \%)$, até 2033, instituídas pela Lei 14.026 de 2020 (BRASIL, 2020). Essa avaliação permite aos gestores estabelecer estratégias regionais e prioridades de implementação do reúso.

Por meio de informações do Atlas Esgotos (ANA, 2017), realizou-se um levantamento da vazão de esgotos gerada por cada município mineiro. A vazão foi analisada em dois cenários: (1) esgoto tratado e (2) esgoto total gerado. Não se considerou, nessa análise, a vazão de esgotos tratada por sistemas individuais, devido à inviabilidade do reúso dessas águas fora da área de geração, sendo possível, nestes casos, apenas o reúso descentralizado.

Os municípios foram agrupados conforme as UPGRHs. Municípios que fazem parte de mais de uma UPGRH foram tratados apenas na unidade na qual se localiza sua sede. A soma da vazão de esgotos gerada por cada município resultou na vazão total gerada na UPGRH.

\section{2 - Demanda pelo uso da água}

Na sequência, foi avaliada a demanda pelo uso da água no estado, por UPGRH, utilizando os dados oficiais do Instituto Mineiro de Gestão das Águas (IGAM), considerando as outorgas e cadastros de usos insignificantes de águas superficiais vigentes no ano de 2019, tabulados em planilha Excel.

Os usos foram classificados conforme a sua finalidade e considerando os seguintes grupos: abastecimento público, consumo industrial, agropecuária (irrigação, dessedentação de animais, aquicultura) e outros usos.

\section{3 - Avaliação disponibilidade $x$ demanda}

Por fim, realizou-se a comparação entre oferta de efluente para reúso e demanda pelo uso da água em cada uma das UPGRHs. Para tal, foram elaborados dois cenários, sendo que 0 primeiro representa a configuração atual, pois considera como disponibilidade a vazão atual de esgoto tratado. Já o segundo cenário trata-se de uma disponibilidade potencial, a ser atingida quando houver a universalização do tratamento de todo o esgoto gerado.

\section{RESULTADOS E DISCUSSÃO}

A apresentação dos resultados utilizará a mesma lógica das etapas metodológicas.

\section{Avaliação da disponibilidade de efluentes para reúso e a demanda de uso existente}

Os dados do Atlas Esgotos (ANA, 2017) de esgoto tratado e gerado foram compilados e agrupados nas UPGRHs e estão apresentados na Tabela 1, cuja coluna final apresenta a relação em percentual entre o esgoto gerado e o tratado.

A distribuição espacial dos dados de esgoto gerado e esgoto tratado está apresentada nas Figuras 1 e 2, respectivamente. Segundo os dados do Atlas Esgotos (ANA, 2017), Minas Gerais somente trata $43,73 \%$ do total de esgoto gerado $\left(28,12 \mathrm{~m}^{3} / \mathrm{s}\right)$, sendo que as UPGRHs SF3, SF5 e PN2 (Figura 2) são as unidades com a maior capacidade de tratamento (superior a 0,5 $\left.\mathrm{m}^{3} / \mathrm{s}\right)$.

A análise das Figuras 1 e 2 permite observar que as unidades com maior geração de esgoto são SF5, PN2, SF3 e PS1. Em relação ao esgoto tratado, estão as unidades SF5, PN2, SF3 e SF10. Vale ressaltar que a Região Metropolitana de Belo Horizonte está localizada justamente nas unidades SF5 e SF3 citadas.

A fim de se avaliar a distribuição espacial da relação de esgoto gerado e tratado, foi elaborada a Figura 3.

Em termos relativos, as unidades GD5, SF5, GD8, SF7, SF10 e PN2 (Figura 3), em ordem crescente, são as unidades com maior capacidade de tratamento (superior a 50\%). Esta análise explicita o desafio em atender as metas de universalização de tratamento de esgoto estabelecidas pela Lei 14.026/2020 (Brasil, 2020), em Minas Gerais, até 2033. Das 10 UPGRHs com maior geração de esgoto (GD2, PN1, GD3, SF2, PS2, DO2, PS1, SF3, PN2 e SF5), em ordem crescente, somente as unidades PN2 (94\%) e SF5 $(61 \%)$ possuem capacidade de tratar acima de $50 \%$ do esgoto gerado.

Os mapas das Figuras 1 e 2 (representação 
da primeira e segunda colunas da Tabela 1) foram apresentados e discutidos em relação aos valores absolutos, com o objetivo não de apresentar índices de geração e tratamento de esgoto, mas de mostrar o potencial em termos de vazão produzida. $O$ mapa da Figura 3 (representação da última coluna da Tabela 1) apresenta exatamente a relação entre o esgoto gerado e o esgoto tratado em cada região, e permite uma visualização do caminho da universalização.

Tabela 1 - Potencial de reúso por UPGRH em Minas Gerais

\begin{tabular}{|c|c|c|c|}
\hline UPGRH $^{\star}$ & \begin{tabular}{|c|} 
Cenário1: \\
Vazão de Esgoto Tratado \\
$\left(\mathrm{m}^{3} / \mathrm{s}\right)$
\end{tabular} & \begin{tabular}{|c|} 
Cenário2: \\
Vazão de Esgoto Gerado \\
$\left(\mathrm{m}^{3} / \mathrm{s}\right)$
\end{tabular} & $\begin{array}{l}\text { \% Esgoto } \\
\text { Tratado }\end{array}$ \\
\hline DO1 & 0,0658 & 0,6736 & $10 \%$ \\
\hline $\mathrm{DO} 2$ & 0,4505 & 0,9612 & $47 \%$ \\
\hline $\mathrm{DO3}$ & 0,0895 & 0,3611 & $25 \%$ \\
\hline DO4 & 0,0339 & 0,6343 & $5 \%$ \\
\hline DO5 & 0,0022 & 0,2347 & $1 \%$ \\
\hline DO6 & 0,0289 & 0,3006 & $10 \%$ \\
\hline GD1 & 0,0027 & 0,1019 & $3 \%$ \\
\hline GD2 & 0,2200 & 0,6889 & $32 \%$ \\
\hline GD3 & 0,2581 & 0,8992 & $29 \%$ \\
\hline GD4 & 0,2080 & 0,6055 & $34 \%$ \\
\hline GD5 & 0,3806 & 0,6661 & $57 \%$ \\
\hline GD6 & 0,0774 & 0,624 & $12 \%$ \\
\hline GD7 & 0,1324 & 0,4388 & $30 \%$ \\
\hline GD8 & 0,2180 & 0,3442 & $63 \%$ \\
\hline PN1 & 0,1100 & 0,696 & $16 \%$ \\
\hline PN2 & 2,8007 & 2,9919 & $94 \%$ \\
\hline PN3 & 0,1061 & 0,3349 & $32 \%$ \\
\hline PS1 & 0,0880 & 1,0989 & $8 \%$ \\
\hline PS2 & 0,0602 & 0,9583 & $6 \%$ \\
\hline SF1 & 0,1516 & 0,3026 & $50 \%$ \\
\hline SF2 & 0,2279 & 0,8995 & $25 \%$ \\
\hline SF3 & 0,6404 & 1,8905 & $34 \%$ \\
\hline SF4 & 0,0640 & 0,2148 & $30 \%$ \\
\hline SF5 & 5,3655 & 8,7783 & $61 \%$ \\
\hline SF6 & 0,0163 & 0,0969 & $17 \%$ \\
\hline SF7 & 0,3039 & 0,4458 & $68 \%$ \\
\hline SF8 & 0,0119 & 0,0599 & $20 \%$ \\
\hline SF9 & 0,0479 & 0,1456 & $33 \%$ \\
\hline SF10 & 0,4515 & 0,6173 & $73 \%$ \\
\hline JQ1 & 0,0240 & 0,0924 & $26 \%$ \\
\hline JQ2 & 0,0216 & 0,1356 & $16 \%$ \\
\hline JQ3 & 0,1502 & 0,3062 & $49 \%$ \\
\hline MU1 & 0,1197 & 0,2372 & $50 \%$ \\
\hline PJ1 & 0,0000 & 0,0827 & $0 \%$ \\
\hline SM1 & 0,0371 & 0,1045 & $36 \%$ \\
\hline PA1 & 0,014 & 0,050 & $28 \%$ \\
\hline
\end{tabular}

${ }^{\star}$ As siglas referem-se àquelas estabelecidas conforme a DN CERH 06/2002 (MINAS GERAIS, 2002) Fonte: Os autores. 
Figura 1 - Representação espacial do total de esgoto gerado em cada UPGRH do estado de Minas Gerais
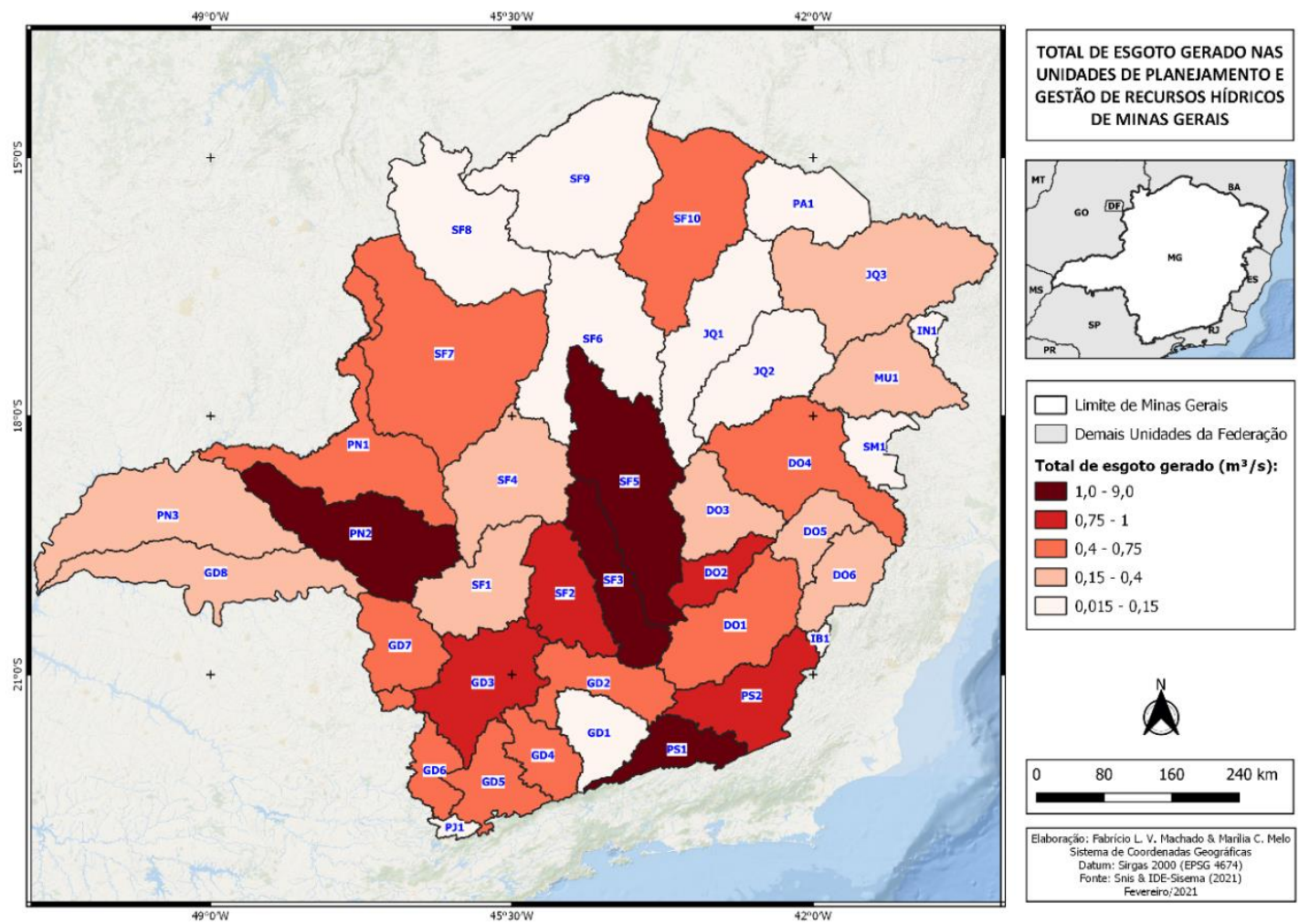

Fonte: Os autores.

Figura 2 - Representação espacial do total de esgoto tratado em cada UPGRH do estado de Minas Gerais
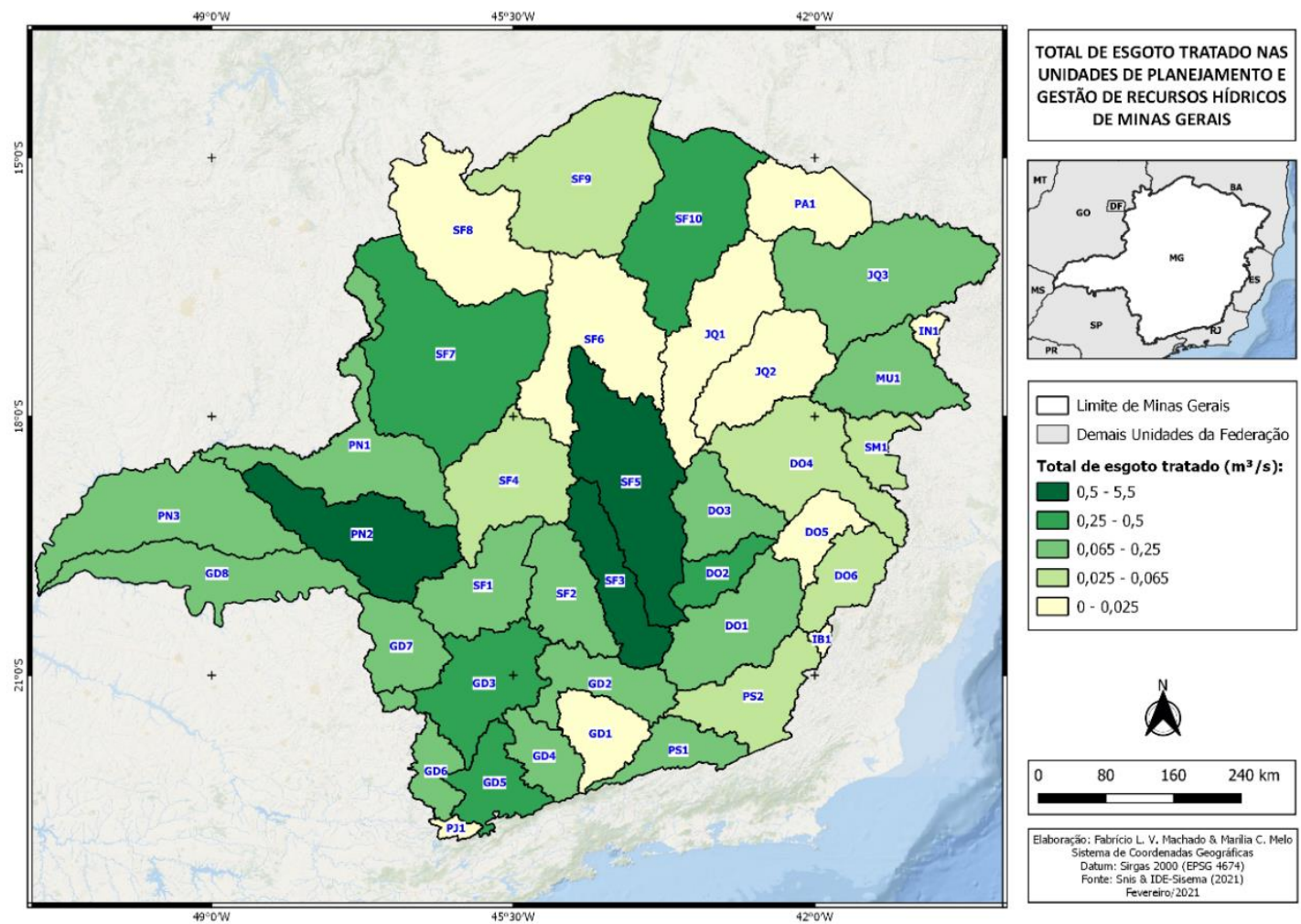

$\square$ Limite de Minas Gerais

$\square$ Demais Unidades da Federação

Total de esgoto tratado $\left(\mathrm{m}^{3} / \mathrm{s}\right)$ :

$\square, 5-5,5$

$\square 0,25-0,5$

$\square 0,065-0,25$

$\square, 025-0,065$

$\square$ - 0,025

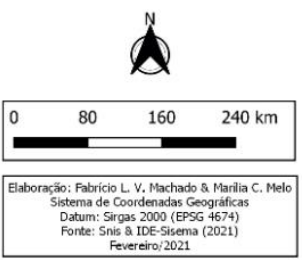

Fonte: Os autores. 


\section{Figura 3 - Representação espacial do percentual do esgoto tratado em relação ao gerado em Minas Gerais}
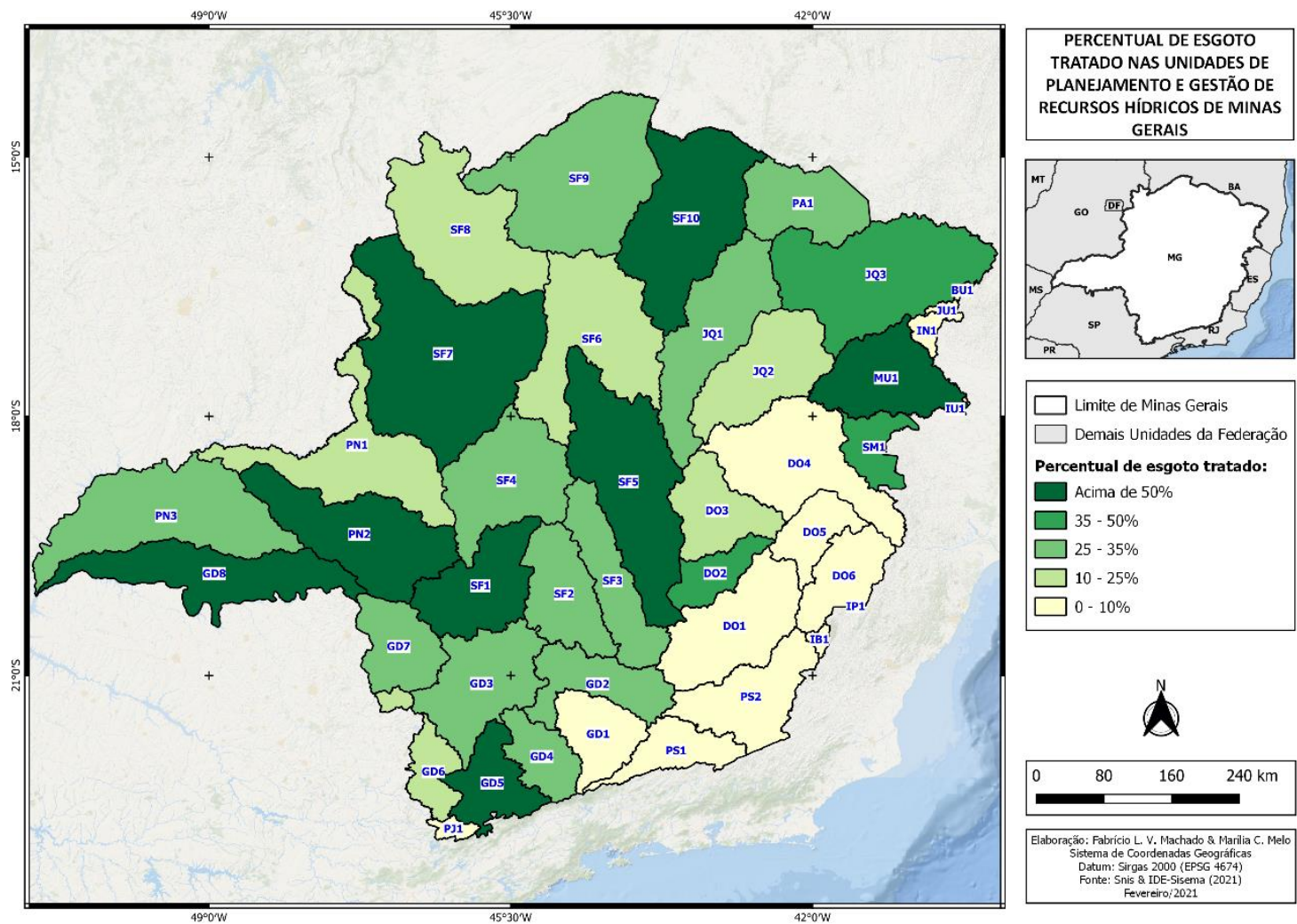

Fonte: Os autores.

\section{Demanda pelo uso da água}

Segundo o IGAM (2020), a demanda por água superficial em Minas Gerais corresponde a $82,8 \%$ da vazão total regularizada. A Tabela 2 apresenta o detalhamento da demanda de água para o estado, considerando a regionalização das UPGRHs e as finalidades de uso.

Observa-se que as 10 unidades que compõem a bacia do rio São Francisco (SF 1 a SF10) correspondem a $54 \%$ da demanda total $\left(561,32 \mathrm{~m}^{3} / \mathrm{s}\right)$, seguido pela bacia do rio Paranaíba (PN1 a PN3) com 27\%. A Figura 4 apresenta espacialização das vazões outorgadas em cada região do Estado.

As UPGRHs SF3, SF5, SF7, SF8, PN1, PN2 e PN3 (Figura 4) são responsáveis pelas maiores demandas (superior a $25 \mathrm{~m}^{3} / \mathrm{s}$ ), sendo que nas unidades SF3 e SF5 predominam o uso para o abastecimento público e consumo humano, enquanto nas demais (SF7, SF8, PN1, PN2 e PN3) o setor agropecuário exerce maior pressão no âmbito regional, conforme Tabela 2 e Figura 4. São exatamente nessas unidades, onde se predomina a irrigação, que ocorre a maior concentração de áreas de conflito declaradas oficialmente pelo órgão gestor, demonstrando uma situação de indisponibilidade hídrica (demanda superior à disponibilidade). Encontramse nessas regiões, também, um importante polo para incentivo ao reúso de água, considerando-se que a irrigação é um relevante uso para efluentes tratados. Adicionalmente, as exigências dos padrões de qualidade e a existência de nutrientes nos efluentes de esgoto tratado reduzem a necessidade de aplicação de fertilizantes agrícolas (JARAMILLO; RESTREPO, 2017; TRIMMER; GUEST, 2018; TORRES et al., 2019; WOLTERSDORF et al., 2018).

\section{Avaliação disponibilidade $\mathrm{x}$ demanda}

A avaliação de potencial de reúso de água, conforme Tabela 3 , indica cenários possíveis. No entanto, vale destacar que o efetivo emprego do reúso possui limitações normativas, relacionadas aos padrões de qualidades admissíveis e a questões logísticas e locacionais. 
Tabela 2 - Demanda hídrica por finalidade nas UPGRH em Minas Gerais

\begin{tabular}{|c|c|c|c|c|c|c|c|c|c|}
\hline \multirow{2}{*}{ UPGRH } & \multicolumn{2}{|c|}{$\begin{array}{l}\text { Abastecimento público / } \\
\text { Consumo humano }\end{array}$} & \multicolumn{2}{|c|}{$\begin{array}{c}\text { Consumo industrial / } \\
\text { Mineração }\end{array}$} & \multicolumn{2}{|c|}{ Agropecuária } & \multicolumn{2}{|c|}{ Outros } & \multirow{2}{*}{$\begin{array}{c}\text { Total } \\
\text { Vazão } \\
\left(\mathrm{m}^{3} / \mathrm{s}\right) \\
\end{array}$} \\
\hline & Vazão $\left(\mathrm{m}^{3} / \mathrm{s}\right)$ & $\%$ & Vazão $\left(\mathrm{m}^{3} / \mathrm{s}\right)$ & $\%$ & $\begin{array}{l}\text { Vazão } \\
\left(\mathrm{m}^{3} / \mathrm{s}\right)\end{array}$ & $\%$ & $\begin{array}{l}\text { Vazão } \\
\left(\mathrm{m}^{3} / \mathrm{s}\right) \\
\end{array}$ & $\%$ & \\
\hline DO1 & 2,809 & $31,6 \%$ & 1,936 & $21,8 \%$ & 3,076 & $34,6 \%$ & 1,078 & $12,1 \%$ & 8,900 \\
\hline DO2 & 3,406 & $35,3 \%$ & 4,980 & $51,7 \%$ & 0,326 & $3,4 \%$ & 0,928 & $9,6 \%$ & 9,640 \\
\hline $\mathrm{DO} 3$ & 1,006 & $33,5 \%$ & 0,412 & $13,7 \%$ & 0,820 & $27,3 \%$ & 0,762 & $25,4 \%$ & 3,000 \\
\hline DO4 & 1,015 & $22,5 \%$ & 0,447 & $9,9 \%$ & 2,376 & $52,7 \%$ & 0,668 & $14,8 \%$ & 4,505 \\
\hline DO6 & 1,139 & $35,1 \%$ & 0,264 & $8,2 \%$ & 1,632 & $50,3 \%$ & 0,207 & $6,4 \%$ & 3,242 \\
\hline GD1 & 0,400 & $13,5 \%$ & 0,249 & $8,4 \%$ & 1,849 & $62,3 \%$ & 0,472 & $15,9 \%$ & 2,969 \\
\hline GD2 & 1,876 & $30,0 \%$ & 1,435 & $23,0 \%$ & 2,368 & $37,9 \%$ & 0,570 & $9,1 \%$ & 6,250 \\
\hline GD3 & 2,475 & $27,8 \%$ & 0,840 & $9,4 \%$ & 4,982 & $56,0 \%$ & 0,605 & $6,8 \%$ & 8,903 \\
\hline GD4 & 1,608 & $31,3 \%$ & 0,579 & $11,3 \%$ & 2,538 & $49,4 \%$ & 0,414 & $8,1 \%$ & 5,140 \\
\hline GD5 & 1,588 & $18,7 \%$ & 1,427 & $16,8 \%$ & 4,851 & $57,2 \%$ & 0,619 & $7,3 \%$ & 8,485 \\
\hline GD7 & 1,126 & $21,9 \%$ & 0,889 & $17,3 \%$ & 2,361 & $45,9 \%$ & 0,766 & $14,9 \%$ & 5,143 \\
\hline GD8 & 4,262 & $28,5 \%$ & 1,509 & $10,1 \%$ & 7,202 & $48,2 \%$ & 1,972 & $13,2 \%$ & 14,946 \\
\hline PN1 & 2,029 & $3,2 \%$ & 1,417 & $2,3 \%$ & 57,334 & $91,4 \%$ & 1,976 & $3,1 \%$ & 62,756 \\
\hline PN2 & 3,332 & $5,5 \%$ & 3,883 & $6,4 \%$ & 50,201 & $82,2 \%$ & 3,634 & $6,0 \%$ & 61,051 \\
\hline PN3 & 2,217 & $8,5 \%$ & 1,069 & $4,1 \%$ & 21,628 & $82,6 \%$ & 1,256 & $4,8 \%$ & 26,170 \\
\hline PS1 & 1,463 & $66,4 \%$ & 0,409 & $18,5 \%$ & 0,173 & $7,9 \%$ & 0,158 & $7,2 \%$ & 2,204 \\
\hline PS2 & 3,098 & $45,0 \%$ & 1,550 & $22,5 \%$ & 1,839 & $26,7 \%$ & 0,400 & $5,8 \%$ & 6,886 \\
\hline SF1 & 1,357 & $19,3 \%$ & 0,599 & $8,5 \%$ & 4,954 & $70,3 \%$ & 0,137 & $1,9 \%$ & 7,047 \\
\hline SF2 & 2,079 & $24,5 \%$ & 1,524 & $17,9 \%$ & 4,657 & $54,8 \%$ & 0,239 & $2,8 \%$ & 8,499 \\
\hline SF3 & 21,979 & $60,8 \%$ & 8,238 & $22,8 \%$ & 5,477 & $15,1 \%$ & 0,463 & $1,3 \%$ & 36,157 \\
\hline SF4 & 0,465 & $6,1 \%$ & 0,250 & $3,3 \%$ & 6,689 & $87,9 \%$ & 0,208 & $2,7 \%$ & 7,612 \\
\hline
\end{tabular}




\begin{tabular}{l|c|c|c|c|c|c|c|c|c}
\cline { 6 - 8 } SF5 & 13,261 & $45,9 \%$ & 4,350 & $15,0 \%$ & 9,850 & $34,1 \%$ & 1,455 & $5,0 \%$ & 28,917 \\
\hline SF6 & 0,855 & $9,1 \%$ & 0,124 & $1,3 \%$ & 7,145 & $75,8 \%$ & 1,302 & $13,8 \%$ & 9,426 \\
\hline SF7 & 1,648 & $1,2 \%$ & 7,298 & $5,4 \%$ & 125,837 & $92,8 \%$ & 0,836 & $0,6 \%$ & 135,618 \\
\hline SF8 & 0,398 & $0,9 \%$ & 0,270 & $0,6 \%$ & 41,489 & $97,9 \%$ & 0,221 & $0,5 \%$ & 42,379 \\
\hline SF9 & 0,617 & $15,0 \%$ & 0,023 & $0,6 \%$ & 3,219 & $78,3 \%$ & 0,254 & $6,2 \%$ & 4,113 \\
\hline SF10 & 1,285 & $7,6 \%$ & 1,190 & $7,1 \%$ & 13,326 & $79,2 \%$ & 1,027 & $6,1 \%$ & 16,828 \\
\hline JQ1 & 0,345 & $23,5 \%$ & 0,058 & $3,9 \%$ & 0,966 & $65,9 \%$ & 0,098 & $6,7 \%$ & 1,467 \\
\hline JQ2 & 0,863 & $18,2 \%$ & 0,190 & $4,0 \%$ & 3,107 & $65,7 \%$ & 0,571 & $12,1 \%$ & 4,730 \\
\hline JQ3 & 0,563 & $11,9 \%$ & 0,368 & $7,8 \%$ & 3,437 & $72,7 \%$ & 0,361 & $7,6 \%$ & 4,730 \\
\hline MU1 & 0,363 & $27,5 \%$ & 0,118 & $9,0 \%$ & 0,744 & $56,4 \%$ & 0,094 & $7,2 \%$ & 1,320 \\
\hline PJ1 & 0,332 & $24,6 \%$ & 0,116 & $8,6 \%$ & 0,502 & $37,2 \%$ & 0,399 & $29,5 \%$ & 1,349 \\
\hline SM1 & 0,180 & $16,2 \%$ & 0,044 & $4,0 \%$ & 0,856 & $77,0 \%$ & 0,032 & $2,9 \%$ & 1,112 \\
\hline PA1 & 0,239 & $12,1 \%$ & 0,049 & $2,5 \%$ & 1,578 & $80,2 \%$ & 0,101 & $5,1 \%$ & 1,967 \\
\hline Total & 84,213 & $15,0 \%$ & 49,077 & $8,7 \%$ & 403,216 & $71,8 \%$ & 24,814 & $4,4 \%$ & 561,320 \\
\hline
\end{tabular}

Fonte: Os autores. 


\section{Figura 4 - Representação espacial da demanda de água outorgada no Estado de Minas Gerais}
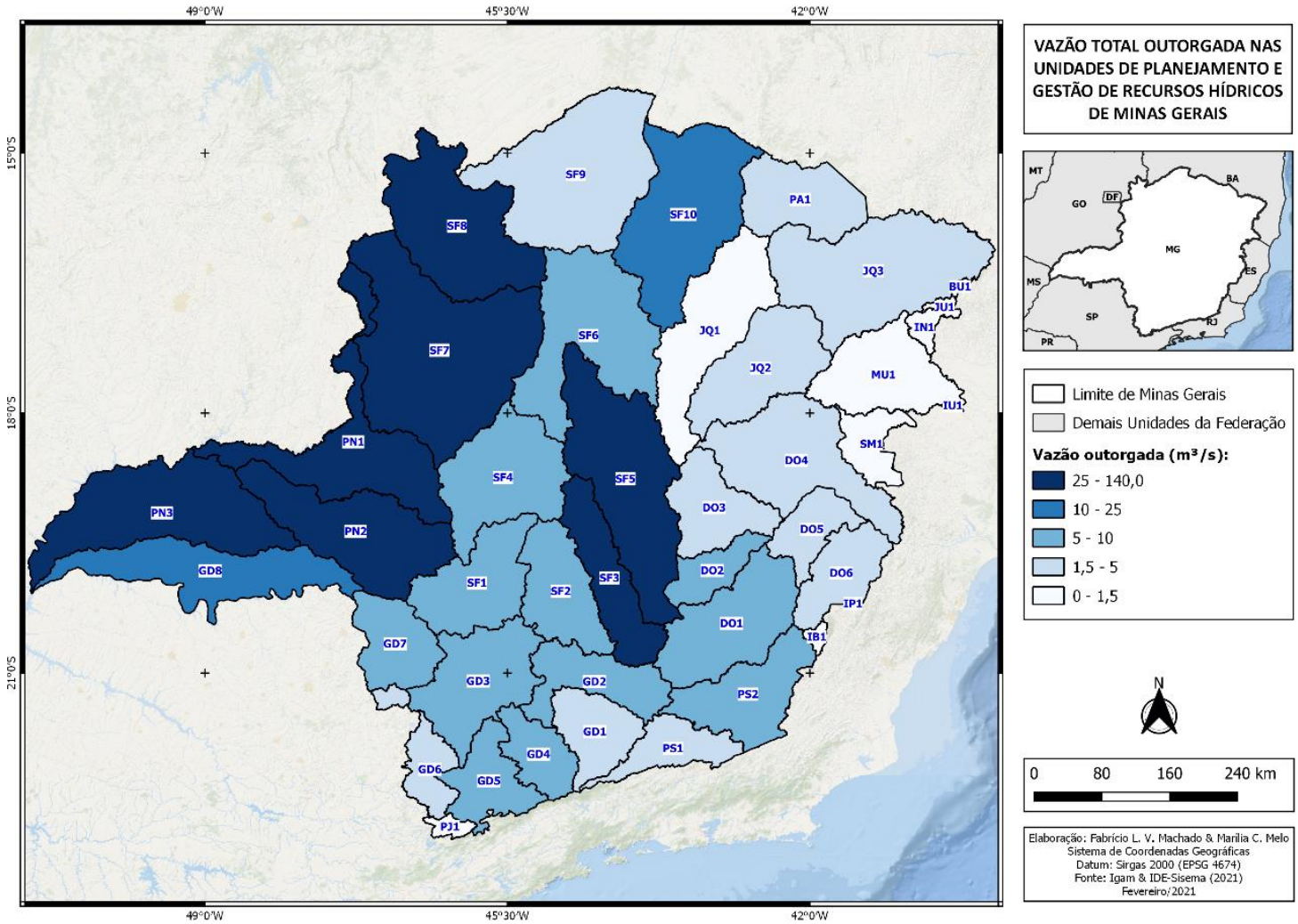

Fonte: Os autores.

Buscando refinar o potencial de reúso, para fins de aproximação com a realidade, as vazões destinadas ao consumo humano e abastecimento público serão desconsideradas, devido à inviabilidade de uso, previstas na Resolução CNRH no 54/2005 (BRASIL, 2005) e Deliberação Normativa CERH no 65/2020 (MINAS GERAIS, 2020). As demais finalidades (consumo industrial/mineração, agropecuária e outros) serão consideradas na sua totalidade. A análise e discussão dos resultados devem considerar a incerteza correspondente à fração cujo emprego da água de reúso não é factível, pelas limitações já referenciadas.

O potencial médio de implantação do reúso em Minas Gerais, considerando o cenário 1 (Tabela 3), corresponde a 2,72\% da demanda dos setores industriais, mineração, agropecuária e outros, com destinação da totalidade do esgoto tratado $\left(12,98 \mathrm{~m}^{3} / \mathrm{s}\right)$. Destacam-se as seguintes UPGRHs com melhor potencial de reúso, considerando o efluente tratado disponível e a demanda pelo uso da água: MU1 (13\%), PS1 $(12 \%)$ e SF5 (34\%). Nestas unidades, o volume de esgoto tratado tem potencial de atender, respectivamente, a 31\%, $51 \%$ e $54 \%$ do setor agrícola. $\mathrm{O}$ atingimento de tais percentuais, ressalvados os fatores logísticos e locacionais, é factível, uma vez que os critérios de qualidade para irrigação é um dos menos restritivos, conforme legislação vigente (MINAS GERAIS, 2020).

Atingindo as metas de universalização estabelecidas no Novo Marco do Saneamento, Lei 14.026 de 2020 (BRASIL, 2020), Minas Gerais poderia atender $5,88 \%$ da atual demanda de água (Tabela 3) com o reúso. Somente na Região Metropolitana de Belo Horizonte (RMBH), integrante das UPGRHs SF3 e SF5, o reúso tem a capacidade de prover um incremento em $30,2 \%$ da vazão destinada a abastecimento público, ao atender $35,7 \%$ da demanda dos demais setores com efluente tratado. Ou seja, a utilização dos efluentes tratados na RMBH para usos, exceto abastecimento público, reduziria a captação de água bruta em $10,67 \mathrm{~m}^{3} / \mathrm{s}$, permitindo, assim, ampliar a disponibilidade hídrica superficial e, portanto, a segurança hídrica para os usos futuros. 
Tabela 3 - Relação demanda x disponibilidade de água de reúso por UPGRH em Minas Gerais

\begin{tabular}{|c|c|c|c|}
\hline UPGRH & $\begin{array}{l}\text { Vazão regularizada } \\
\left(\mathrm{m}^{3} / \mathrm{s}\right)\end{array}$ & $\begin{array}{c}\text { Cenário 1: Relação demanda } x \\
\text { disponibilidade }\end{array}$ & $\begin{array}{c}\text { Cenário 2: } \\
\text { Relação demanda } \\
\text { x disponibilidade }\end{array}$ \\
\hline DO1 & 6,090 & $1 \%$ & $11 \%$ \\
\hline $\mathrm{DO} 2$ & 6,234 & $7 \%$ & $15 \%$ \\
\hline $\mathrm{DO3}$ & 1,994 & $4 \%$ & $18 \%$ \\
\hline DO4 & 3,491 & $1 \%$ & $18 \%$ \\
\hline DO5 & 1,626 & $0 \%$ & $14 \%$ \\
\hline DO6 & 2,103 & $1 \%$ & $14 \%$ \\
\hline GD1 & 2,570 & $0 \%$ & $4 \%$ \\
\hline GD2 & 4,374 & $5 \%$ & $16 \%$ \\
\hline GD3 & 6,428 & $4 \%$ & $14 \%$ \\
\hline GD4 & 3,532 & $6 \%$ & $17 \%$ \\
\hline GD5 & 6,897 & $6 \%$ & $10 \%$ \\
\hline GD6 & 3,696 & $2 \%$ & $17 \%$ \\
\hline GD7 & 4,017 & $3 \%$ & $11 \%$ \\
\hline GD8 & 10,683 & $2 \%$ & $3 \%$ \\
\hline PN1 & 60,727 & $0 \%$ & $1 \%$ \\
\hline PN2 & 57,718 & $5 \%$ & $5 \%$ \\
\hline PN3 & 23,953 & $0 \%$ & $1 \%$ \\
\hline PS1 & 0,740 & $12 \%$ & $148 \%$ \\
\hline PS2 & 3,789 & $2 \%$ & $25 \%$ \\
\hline SF1 & 5,690 & $3 \%$ & $5 \%$ \\
\hline SF2 & 6,420 & $4 \%$ & $14 \%$ \\
\hline SF3 & 14,178 & $5 \%$ & $13 \%$ \\
\hline SF4 & 7,147 & $1 \%$ & $3 \%$ \\
\hline SF5 & 15,656 & $34 \%$ & $56 \%$ \\
\hline SF6 & 8,571 & $0 \%$ & $1 \%$ \\
\hline SF7 & 133,970 & $0 \%$ & $0 \%$ \\
\hline SF8 & 41,981 & $0 \%$ & $0 \%$ \\
\hline SF9 & 3,496 & $1 \%$ & $4 \%$ \\
\hline SF10 & 15,543 & $3 \%$ & $4 \%$ \\
\hline JQ1 & 1,122 & $2 \%$ & $8 \%$ \\
\hline JQ2 & 3,867 & $1 \%$ & $4 \%$ \\
\hline JQ3 & 4,167 & $4 \%$ & $7 \%$ \\
\hline MU1 & 0,957 & $13 \%$ & $25 \%$ \\
\hline PJ1 & 1,017 & $0 \%$ & $8 \%$ \\
\hline SM1 & 0,931 & $4 \%$ & $11 \%$ \\
\hline PA1 & 1,728 & $1 \%$ & $3 \%$ \\
\hline
\end{tabular}

Fonte: Os autores.

As Figuras 5 e 6 foram produzidas, a partir dos dados das Tabelas 1 e 3, para avaliar se são coincidentes as regiões com maior demanda pelo uso da água e aquelas que possuem maior potencial de disponibilidade de esgoto para reúso (em ambos os cenários).

Pode-se observar que apenas 4 (quatro) unidades são coincidentes nas duas análises (SF5, PN1, PN2e SF3), entretanto, elas não se encontram na mesma posição de prioridade nas 
duas listas. Por exemplo, a SF5 é a que mais tem disponibilidade de efluente para reúso, no entanto, encontra-se na sexta posição de unidade em relação à demanda.

Figura 5 - As 10 UPGRHs com a maior demanda pelo uso da água

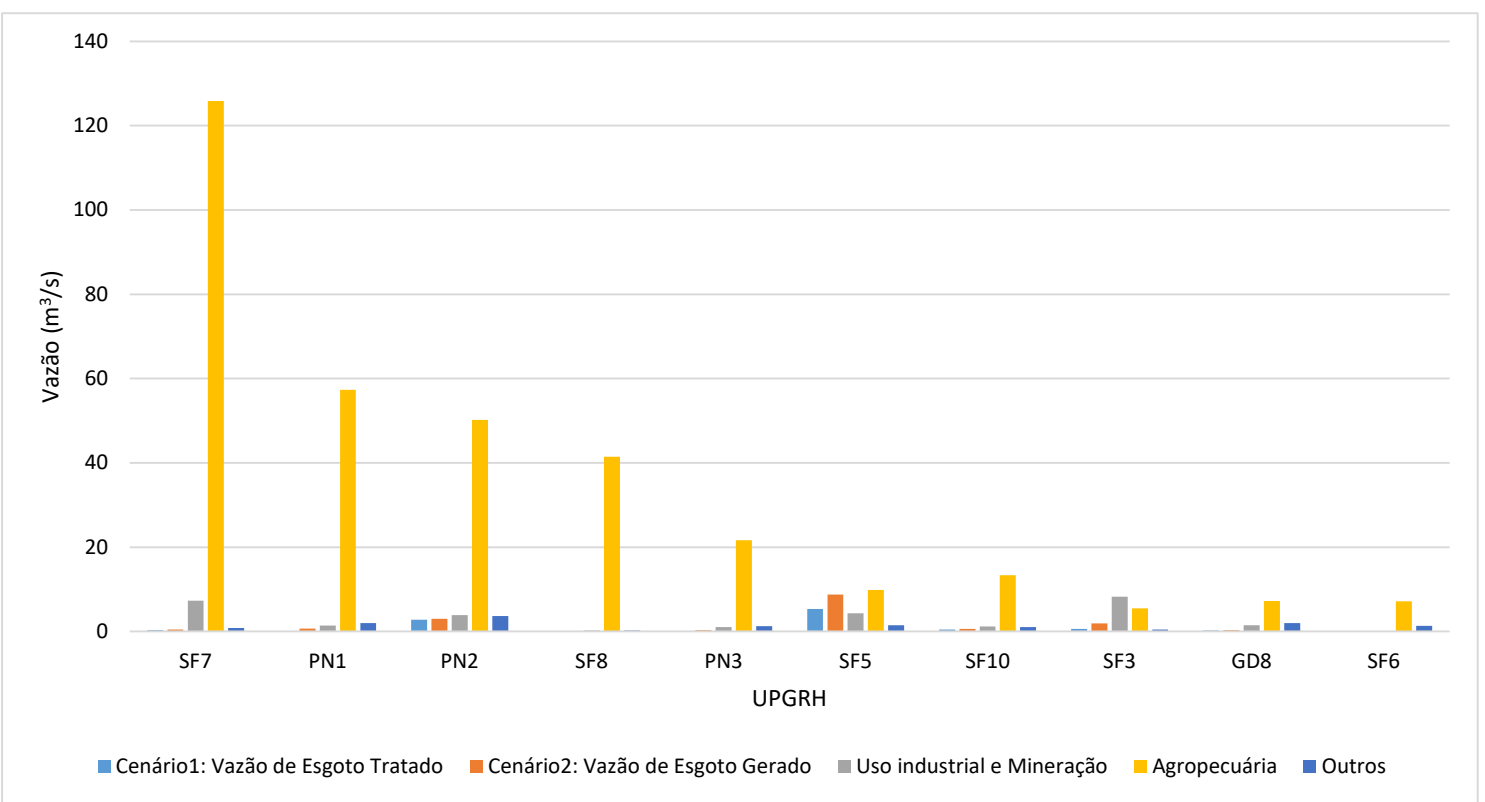

Fonte: Os autores.

Figura 6 - As 10 UPGRHs com a maior disponibilidade de efluentes para reuso (Cenário 2)

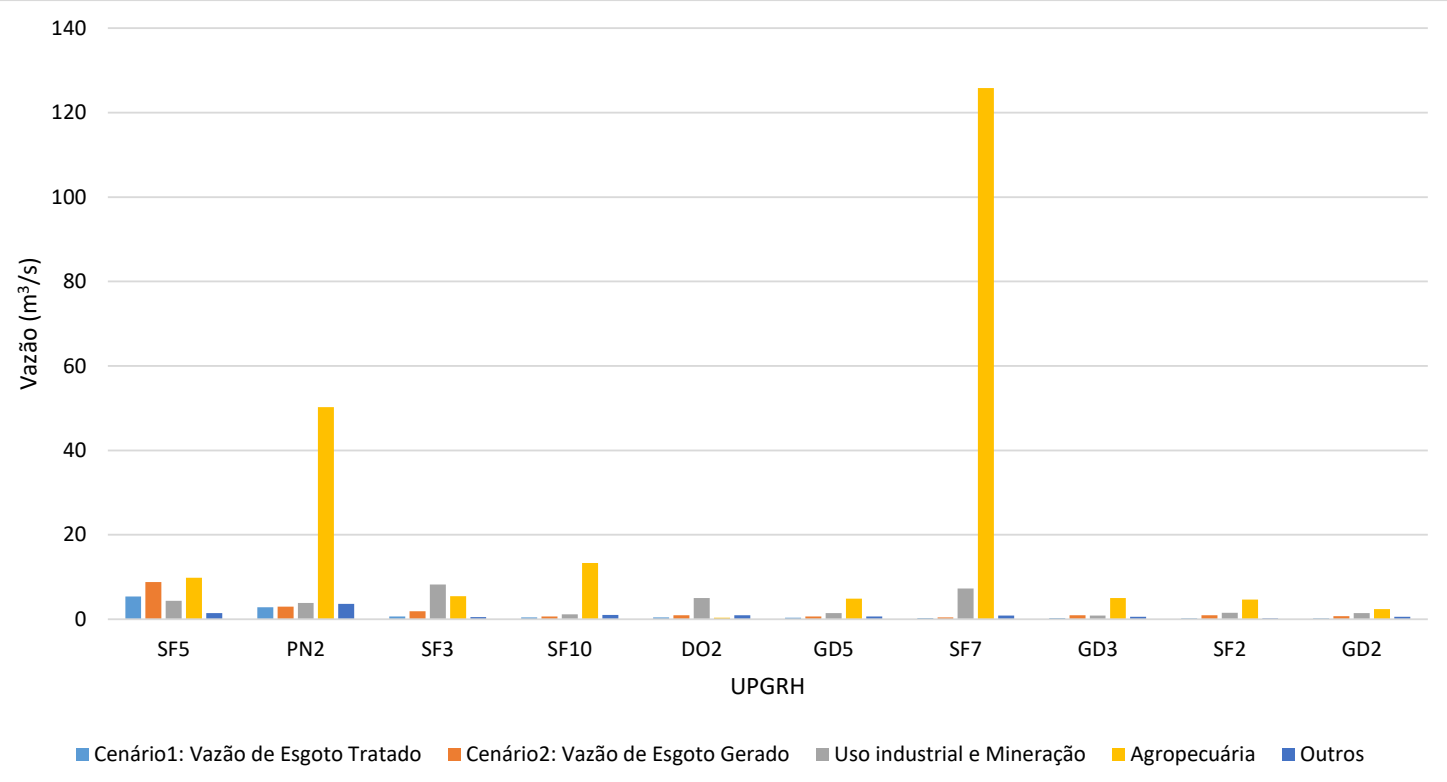

Fonte: Os autores.

A avaliação do potencial de reúso realizada no presente trabalho teve um enfoque exclusivamente na vazão disponível e na demanda pelo uso da água existente. Entretanto, sabe-se que os requisitos de qualidade são cruciais para tornar-se, de fato, factível a utilização de um efluente doméstico tratado. Em Minas Gerais, o reúso foi regulamentado por meio 
da DN CERH no 65 de 18 de junho de 2020, norma esta que estabelece os padrões de qualidade dos efluentes adequados à finalidade de uso que se pretende fazer (MINAS GERAIS, 2020).

Estudo realizado por Chernicharo et al. (2018) buscou apresentar as tecnologias mais empregadas para tratamento de esgoto sanitário nas regiões Sul, Sudeste e Centro-Oeste do Brasil. O estudo concluiu que, especificamente quanto aos entes federativos avaliados, os reatores anaeróbicos UASB (Upflow Anaerobic Sludge Blanket) são preferencialmente selecionados no Paraná, Minas Gerais, Mato Grosso do Sul e no Distrito Federal, para todos os portes de ETEs.

Conforme informações tabulares do Atlas Esgoto (ANA, 2019b), o reator anaeróbico compõe a maioria dos sistemas de tratamento de efluentes ativos nas regiões Sul $(56,54 \%)$, Centro-oeste $(37,25 \%)$ e Nordeste $(35,48 \%)$. Na região Norte, predominam sistemas compostos por fossas sépticas (33.49\%) e na região sudeste, sistemas compostos por lagoas (32,63\%).

Em Minas Gerais, o referido estudo indica que, das 441 Estações de Tratamento de Esgotos mapeadas em Minas Gerais, 315 (71\%) usam o reator UASB como principal etapa do processo de tratamento de efluentes. Destas, 80 ETE's (18\%) adotam o reator como única etapa do tratamento, 82 (19\%) utilizam a combinação Reator Anaeróbio + Filtro Aeróbio + Decantador, 68 $(15 \%)$ Reator anaeróbio + Filtro e $36(8 \%)$ a combinação Reator anaeróbio + algum tipo de Lagoa.

Sobre as principais tecnologias adotadas, os reatores UASB são unidades de tratamento anaeróbio que se prestam, fundamentalmente, à remoção de matéria orgânica carbonácea em suspensão ou dissolvida nas águas residuárias (LOBATO, 2011). Calijuri et al. (2009) demonstraram que, durante 0 período considerado (19 meses) em uma unidade experimental, o reator UASB apresentou elevada remoção de DBO5, DQO e SST e capacidade de amortecer as variações das concentrações afluentes: valores médios de 77 a 84\% (DBO), 69 a $75 \%$ (DQO), respectivamente nos meses mais frios e mais quentes e $76 \%$ como média geral para SST. Observou-se, também, como média geral, remoção de fósforo em torno de $15 \%$, além de notável conversão de parte do nitrogênio orgânico em nitrogênio amoniacal (em geral, em torno de $40 \%$, sendo cerca de 30 e $50 \%$, respectivamente, nos períodos quente e frio). Como esperado, a remoção de coliformes mostrou-se limitada: $87 \% \quad(0,89 \log 10)$ para coliformes totais e $67 \%(0,48 \log 10)$ para E. coli. Mesmo o reator UASB apresentando elevada eficiência de remoção de matéria orgânica e de sólidos, confirma-se a necessidade do polimento de seu efluente.

Segundo Chernicharo et al. (2001), a remoção de coliformes nos reatores anaeróbios tem baixa eficiência, usualmente na ordem de uma unidade logarítmica e há poucos estudos que abordam a remoção de helmintos, vírus e protozoários nesses reatores.

A remoção de ovos de helmintos nos reatores UASB que tem sido relatada são da ordem de 60 a $90 \%$, o que é insuficiente para a produção de efluentes que possam ser utilizados na irrigação. Logo, o efluente do reator UASB exige póstratamento para produzir esgotos tratados com características de qualidade sanitária (CAVALCANTI et al., 2000 apud SYLVESTRE, 2013).

Considerando que a tecnologia preferencial para tratamento dos esgotos sanitários em Minas Gerais não apresenta boa eficiência de remoção de E. coli e ovos de helmintos, é possível que os efluentes tratados demandem polimento antes de serem disponibilizados para reúso.

Neste contexto, com objetivo de remoção de patógenos, as lagoas de estabilização podem se apresentar como uma alternativa atraente para pós-tratamento de efluentes de reatores UASB. As lagoas mantêm, no todo, a simplicidade conceitual já assumida para os reatores anaeróbios. Esta linha de se combinar reatores de manta de lodo com lagoas de estabilização figura-se como de aplicabilidade extremamente ampla para o Brasil (VON SPERLING, 1996).

Nas lagoas de estabilização, podem ser alcançados excelentes níveis de remoção de patogênicos, atingindo valores na ordem de $99,99 \%$ de remoção de coliformes termotolerantes, sendo, portanto, um excelente processo de tratamento, em regiões onde o objetivo de balneabilidade no corpo receptor é importante, ou no que se refere a níveis máximos de organismos admissíveis para águas de abastecimento público (MARA, 1996, apud NASCIMENTO, 2001).

Apesar de apresentarem-se como boa alternativa para remoção de patógenos, apenas 
8\% das ETE's implantadas em Minas Gerais utilizam as lagoas para polimento dos efluentes pós-reator anaeróbio. A baixa adoção de polimento, que vise à remoção de patógenos, pode ser justificada pela ausência de padrões para indicadores de contaminação fecal, entre os parâmetros para lançamento de efluentes sanitários dispostos na Deliberação Normativa Conjunta do Conselho de Política Ambiental e Conselho Estadual de Recursos Hídricos ํㅜ 01 de 05 de maio de 2008 (MINAS GERAIS, 2008).

$\mathrm{Na}$ Deliberação Normativa CERH-MG № 65, de 18 de junho de 2020 (MINAS GERAIS, 2020), os padrões microbiológicos para reúso são coliformes termotolerantes ou E. coli (NMP/100 $\mathrm{mL}$ ) e ovos viáveis de helmintos. Os valores de referência variam de acordo com a modalidade em que a água será utilizada. $A$ água para reúso é passível de utilização nas modalidades agrossilvipastoris, urbanos, usos para fins ambientais e usos industriais.

Considerando que os indicadores para reúso reforçam a necessidade de se ter um processo de tratamento de efluentes com boa eficiência para remoção de patógenos, os sistemas preferenciais adotados em Minas Gerais podem não ser suficientes para produzir água de reúso. Esta é uma importante discussão para a implantação da política pública de saneamento no estado, considerando a importância do reúso para segurança hídrica, além de ser um instrumento referenciado no Marco do saneamento (BRASIL, 2020) que constará como meta em contratos de concessão.

\section{CONCLUSÕES}

Minas Gerais possui, em 2021, um "potencial parcialmente instalado" médio de produção de água de reúso a partir de esgotos domésticos da ordem de $3 \%$ para setores industriais, mineração, agropecuária e outros, com destinação da totalidade do esgoto tratado $\left(12,98 \mathrm{~m}^{3} / \mathrm{s}\right)$. As UPGRHs com maior potencial de produção de água de reúso são: PS1 (12\%) e SF5 (34\%). Nestas unidades, o volume de esgoto tratado tem potencial de atender, respectivamente, a $51 \%$ e $54 \%$ do setor agrícola.

${ }^{1}$ A depender dos requisitos de qualidade do uso e da qualidade do efluente tratado
Em cenário futuro, tendo sido atingidas as metas estabelecidas pela Lei Federal 14.026 de 2020, Minas Gerais poderia atender com água de reúso $12 \%$ da atual demanda de água. $\mathrm{Na}$ Região Metropolitana de Belo Horizonte, integrante das UPGRH's SF3 e SF5, o reúso tem potencialidade de prover um incremento de $30,2 \%$ na disponibilidade de água nova para abastecimento público à medida que supri $35,7 \%$ da demanda por água dos demais setores.

Apesar do potencial de produção de água para reúso, os sistemas de tratamento majoritários em Minas Gerais têm baixa eficiência em remoção de patógenos, um dos parâmetros adotados no Estado para viabilizar o reúso da água. Desta forma, para que os empreendimentos de tratamento de esgotos sanitários sejam produtores diretos de água de reúso, é necessário adotar melhorias no sistema de tratamento, de forma a aumentar a eficiência de remoção de patógenos.

Enfim, observa-se que Minas Gerais tem um arcabouço institucional pronto para a implementação do reúso, entretanto, com poucas práticas ainda sendo realizadas. Deve-se, assim, estabelecer uma política de incentivo ao reúso considerando a sua potencialidade do reúso como fonte alternativa e capaz de reduzir o conflito pelo uso da água em regiões agrícolas no estado. Outro ponto importante está no fato de se planejar o incremento de tratamento de esgoto de forma articulada com os possíveis consumidores de reúso, a fim de se facilitar a logística de transporte entre a fonte de efluente tratado e o potencial utilizador dele.

\section{REFERÊNCIAS}

AGÊNCIA NACIONAL DE ÁGUAS E SANEAMENTO BÁSICO. Atlas Esgotos: despoluição de bacias hidrográficas, 88p. Brasília, 2017.

\section{Conjuntura dos Recursos Hídricos no \\ Brasil 2017. Brasília, 2018. \\ Conjuntura dos Recursos Hídricos no \\ Brasil 2018. Brasília, 2019a.}

Atlas Esgotos: Estações de Tratamento de Esgoto. Planilha eletrônica. 2019b. Disponível em: https://metadados.snirh.gov.br/geonetwork/srv/por/catal og.search\#/metadata/1d8cea87-3d7b-49ff-86b8966d96c9eb01. Acesso em: 01 maio 2021. 
. Atlas Irrigação: Uso da água na agricultura irrigada. 2. ed. Brasília, 2021.

ALKAISI A.: MOSSAD, R.; SHARIFIAN-

BARFOROUSH, A. A review of the water desalination systems integrated with renewable energy. Energy Procedia, v. 110, p. 268-274, 2017.

ANGELAKIS, A.N.; ASANO, T.; BAHRI, A.; JIMENEZ, B.E.; TCHOBANOGLOUS, G. Water reuse: from ancient to modern times and the future. Frontiers in Environmental Science, v. 6, n. 26, p. 1-17, 2018.

BRASIL. Resolução no 54 de $\mathbf{2 8}$ de novembro de 2005. Estabelece modalidades, diretrizes e critérios gerais para a prática de reúso direto não potável de água, e dá outras providências. Brasília, 2005.

\section{Resolução no 121 de 16 de dezembro de}

2010. Estabelece diretrizes e critérios para a prática de reúso direto não potável de água na modalidade agrícola e florestal, definida na Resolução CNRH no 54 , de 28 de novembro de 2005. Brasília, 2010.

Lei no 14.026, de 15 de julho de 2020.

Atualiza o marco legal do saneamento básico. Brasília, 2020.

CALIJURI, M.L.; BASTOS, R.K.X.; MAGALHÃES, T.B.; CAPELETE, B.C.; DIAS, E.H.O. Tratamento de esgotos sanitários em sistemas reatores UASB/wetlands construídas de fluxo horizontal: eficiência e estabilidade de remoção de matéria orgânica, sólidos, nutrientes e coliformes. Engenharia. Sanitária Ambiental, v. 14, n. 3, p. 421-430, 2009.

CHERNICHARO, C.A.L.; VAN HAANDEL, A.C.; CYBIS, L.F. CYBIS, E.F Introdução. In: Programa de pesquisa em saneamento básico: Pós-tratamento de efluentes de reatores anaeróbios. Brasília: PROSAB/FINEP, 2001. p.19-34.

; RIBEIRO, T.B.; GARCIA, G.B.;

LERMONTOV, A.; PLATZER, C.J.; POSSETTI, G.R.C.; ROSSETO, M.A.L.L. Panorama do tratamento de esgoto sanitário nas regiões Sul, Sudeste e CentroOeste do Brasil: tecnologias mais empregadas. Revista DAE, v. 66, n. 213, p. 5-19, 2018.

FONSECA, M.; MELO, M.; RIBEIRO, R. Uma avaliação da progressão do uso da água no Estado de Minas Gerias, Brasil. In: CONGRESSO NACIONAL DO MEIO AMBIENTE, 17., 2020, Poços de Caldas. Anais... Poços de Caldas-MG: GSC Eventos, 2020. v. 12, n.1.

HELMECKE, M.; FRIES, E.; SCHULTE, C. Regulating water reuse for agricultural irrigation: risks related to organic micro-contaminants. Environmental Science Europe, v. 32, n. 4, p. 1-10, 2020.
HESPANHOL, I. Um novo paradigma para a gestão de recursos hídricos. Estudos Avançados, v. 22, n. 63, p. 131-158, 2008.

INSTITUTO MINEIRO DE GESTÃO DAS ÁGUAS. Relatório de Gestão e Situação dos Recursos Hídricos de Minas Gerais - 2019: 20 anos da lei mineira das águas. Belo Horizonte, 2019.

Relatório de Gestão e Situação dos

Recursos Hídricos de Minas Gerais - 2020:

Segurança Hídrica. Belo Horizonte, 2020.

Relatório de Gestão e Situação dos

Recursos Hídricos de Minas Gerais - 2014 a 2017. Belo Horizonte, 2018. Disponível em:

http://portalinfohidro.igam.mg.gov.br/images/Conjuntura _2017.pdf. Acesso em: 18 fev. 2021.

JARAMILLO, M. F.; RESTREPO, I. Wastewater reuse in agriculture: A review about its limitations and benefits. Sustainability, v. 9, p. 1734, 2017.

KONCAGÜL, E.; TRAN, M.; CONNOR, R.; UHLENBROOK, S. Relatório mundial das Nações Unidas sobre desenvolvimento dos recursos hídricos 2019: não deixar ninguém para trás, fatos e dados. Unesco World Water Assessment Programme, 2019.

LOBATO, L.C.S. Aproveitamento energético de biogás gerado em reatores Uasb tratando esgoto doméstico. Tese (doutorado) - Universidade Federal de Minas Gerais, Escola de Engenharia, Belo Horizonte, 2011.

MELO, M.C.; SANTOS, A.S.P.; SANTOS, N.A.P.; ARAÚJO, B.M.; OLIVEIRA, J. R.S.; COMPOS, A.R. Evaluation of potential use of domestic treated effluents for irrigation in areas subject to conflicts over water use in Paracatu river basin. Revista Caminhos de Geografia, v. 21, n. 75, p. 52-63, 2020.

\section{MINAS GERAIS. Deliberação Normativa CERH-MG} no 06 de 04 de outubro de 2002. Estabelece as Unidades de Planejamento e Gestão de Recursos Hídricos do Estado de Minas Gerais. Belo Horizonte, 2002.

Deliberação Normativa Conjunta COPAM/CERH-MG no 01 de 05 de maio de 2008. Dispõe sobre a classificação dos corpos de água e diretrizes ambientais para o seu enquadramento, bem como estabelece as condições e padrões de lançamento de efluentes, e dá outras providências. Belo Horizonte, 2008.

Deliberação Normativa CERH-MG n 65, de 18 de junho de 2020. Estabelece diretrizes, modalidades e procedimentos para o reúso direto de água não potável, proveniente de Estações de 
Tratamento de Esgotos Sanitários (ETE) de sistemas públicos e privados e dá outras providências. Belo Horizonte, 2020.

MOURA, P.G.; ARANHA, F.N.; HANDAM, N.B.; MARTIN, L.E.; SALLES, M.J.; CARVAJAL, E.; JARDIM, R.; SOTERO-MARTINS, A. Água de reúso: uma alternativa sustentável para o Brasil. Engenharia Sanitária e Ambiental, Rio de Janeiro, v. 25, n. 6, p. 791-808, 2020.

NASCIMENTO, J. R. S. Lagoas de alta taxa de produção de algas para pós-tratamento de efluentes de reatores anaeróbios. Dissertação (Mestrado) - Universidade Federal do Rio Grande do Sul, Porto Alegre, 2001.

PEREIRA, V.R.; RODRIGUEZ, D.A.; COUTINHO, S.M.V.; SANTOS, D.V.; MARENGO, J.A. Adaptation opportunities for water security in Brazil. Sustainability in Debate, v. 11, n. 3, p. 91-121, 2020.

PINTO, H.S.; FARIA, I.D.; BAPTISTA, R.; KASSMAYER, K.; ABBUD, A.; PINTO, V.C. A crise hídrica e suas consequências. Brasil: Núcleo de Estudo e Pesquisas, Senado Federal, 2014. 32p.

SANTOS, A.S.P.; GONÇALVES, R.F.; MELO, M.C.; LIMA, M.A.M.; ARAUJO, B.M. Uma análise crítica sobre os padrões de qualidade de água de uso e de reúso no Brasil. Revista Sustinere, [S.I.], v. 8, n. 2, p. 437- 462, 2020.

SGROI, M.; VAGLIASINDI, F.G. A.; ROCCARO, P. Feasibility, sustainability and circular economy concepts in water reuse. Current Opinion in Environmental Science \& Health, v. 2, p. 20-25, 2018.

SILVA JR.; L.C.; ARAUJO, B.M.; SANTOS, A.S.P.; OBRACZKA, M. BOTTREL, S.E.C. Panorama do reúso de água das estações de tratamento de esgotos da região Sudeste. In: CONGRESSO BRASILEIRO DE ENGENHARIA AMBIENTAL E SANITÁRIA, 30., 2019, Natal/RN, 2019. Anais... Rio de Janeiro: ABES, 2019.
SMOL M.; ADAM C.; PREISNER M. Circular economy model framework in the European water and wastewater sector. J. Mater. Cycles Waste Management, v. 22, p. 682-697, 2020.

SYLVESTRE, S. H. Z. Desempenho de sistemas de reatores anaeróbios e aeróbio na remoção de coliformes e ovos de helmintos de águas residuárias de suinocultura. Dissertação (Mestrado) - Universidade Estadual Paulista, Jaboticabal, 2013.

THE UNITED NATIONS WORLD WATER DEVELOPMENT. Water and Jobs. United Nations World Water Assessment Programme. Unesco. Paris, 2016.

TORRES, D. M. Tratamento de efluentes e produção de água de reúso para fins agrícolas. Holos, [S.I.], v. 8, p. $1-15,2019$.

TRIMMER, J. T.; GUEST, J. S. Recirculation of humanderived nutrients from cities to agriculture across six continents. Nature Sustainability, v. 1, p. 427-435, 2018.

VON SPERLING, M. Princípios de tratamento biológicos de águas residuárias. Belo Horizonte: Departamento de Engenharia Sanitária e Ambiental, Universidade Federal de Minas Gerais, 1996. v. 3., $134 p$.

VOULVOULIS, N. Water reuse from a circular economy perspective and potential risks from an unregulated approach. Current Opinion in Environmental Science \& Health, v. 2, p. 32-45, 2018.

WOLTERSDORF, L.; ZIMMERMANN, M.; DEFFNER, J.; GERLACH, M.; LIEHR, S.; Benefits of an integrated water and nutrient reuse system for urban areas in semi-arid developing countries. Resources, Conservation and Recycling, v. 128, p. 382-393, 2018. 